\title{
Identification of four novel DC-SIGN ligands on Mycobacterium bovis BCG
}

\author{
Maria V. Carroll ${ }^{1}$, Robert B. Sim ${ }^{1}$, Fabiana Bigi ${ }^{2}$, Anne Jäkel ${ }^{1}$, Robin Antrobus ${ }^{3}$, Daniel A. Mitchell ${ }^{4} \bowtie$ \\ 1 Department of Pharmacology, University of Oxford, Mansfield Road, Oxford OX1 3QT, UK \\ 2 Institute of Biotechnology, CICVyA-INTA, Los Reseros y Las Cabañas, 1712 Castelar, Argentina \\ ${ }^{3}$ Cambridge Institute of Medical Research, Addenbrooke's Hospital, Hills Road, Cambridge CB2 OXY, UK \\ ${ }^{4}$ CSRI-UHCW Walsgrave Campus, University of Warwick, Coventry, CV2 2DX, UK \\ \ Correspondence: D.Mitchell@warwick.ac.uk \\ Received June 29, 2010 Accepted August 3, 2010
}

\section{ABSTRACT}

Dendritic-cell-specific intercellular adhesion molecule-3grabbing non-integrin (DC-SIGN; CD209) has an important role in mediating adherence of Mycobacteria species, including $M$. tuberculosis and M. bovis BCG to human dendritic cells and macrophages, in which these bacteria can survive intracellularly. DC-SIGN is a C-type lectin, and interactions with mycobacterial cells are believed to occur via mannosylated structures on the mycobacterial surface. Recent studies suggest more varied modes of binding to multiple mycobacterial ligands. Here we identify, by affinity chromatography and mass-spectrometry, four novel ligands of $M$. bovis BCG that bind to DC-SIGN. The novel ligands are chaperone protein DnaK, 60 kDa chaperonin-1 (Cpn60.1), glyceraldehyde-3 phosphate dehydrogenase (GAPDH) and lipoprotein IprG. Other published work strongly suggests that these are on the cell surface. Of these ligands, IprG appears to bind DC-SIGN via typical proteinglycan interactions, but DnaK and Cpn60.1 binding do not show evidence of carbohydrate-dependent interactions. LprG was also identified as a ligand for DC-SIGNR (L-SIGN; CD299) and the M. tuberculosis orthologue of IprG has been found previously to interact with human toll-like receptor 2. Collectively, these findings offer new targets for combating mycobacterial adhesion and within-host survival, and reinforce the role of DCSIGN as an important host ligand in mycobacterial infection.

KEYWORDS DC-SIGN, Mycobacteria, lectins

\section{INTRODUCTION}

Tuberculosis is the world's most prevalent infectious disease affecting a third of the global human population. The causative agent of tuberculosis, Mycobacterium tuberculosis, avoids the destructive capacity of the host immune system by residing inside the phagosome of host mononuclear phagocytes (Armstrong and Hart, 1975; Clemens and Horwitz, 1995; Sturgill-Koszycki et al., 1996). Many studies have shown that $M$. tuberculosis, M. paratuberculosis and M. bovis BCG can bind to dendritic-cell-specific intercellular adhesion molecule-3-grabbing non-integrin (DC-SIGN/CD209) to promote entry into human dendritic cells (DCs) and alveolar macrophages (Geijtenbeek et al., 2003; Maeda et al., 2003; Tailleux et al., 2003; Pitarque et al., 2005; Appelmelk et al., 2008). A recent study indicates that a mutation of DC-SIGN causing lower expression is protective against tuberculosisinduced lung cavitation (Vannberg et al., 2008). DC-SIGN is a $44 \mathrm{kDa}$ type II transmembrane protein that consists of a carbohydrate recognition domain, neck domain, transmembrane domain and cytoplasmic tail. It is expressed mainly on DCs and on selected macrophage populations including alveolar macrophages (Geijtenbeek et al., 2000a; Lee et al., 2001; Maeda et al., 2003). DC-SIGN is a calcium-dependent lectin and has a high affinity for mannosylated surfaces, forming tetrameric complexes when binding to high mannose glycoproteins, such as HIV gp120 (Geijtenbeek et al., 2000b; Feinberg et al., 2001; Mitchell et al., 2001; Appelmelk et al., 2003). DC-SIGN has been shown to bind lipolysaccharide $L e^{x}$ and mannose structures found on bacteria, such as Helicobacter pylori, Klebsiella pneumonia and M. tuberculosis (Appelmelk et al., 2003; Geijtenbeek et al., 2003; Tailleux et 
al., 2003; van Kooyk and Geijtenbeek, 2003). Using purified cell wall components from mycobacteria, DC-SIGN was shown to bind lipoarabinomannan (LAM) structures from $M$. tuberculosis, M. bovis and M. bovis BCG, all of which express mannose-capped LAM (ManLAM). However, LAM purified from $M$. smegmatis did not bind DC-SIGN, since it expresses uncapped LAM, so-called AraLAM. Similarly, LAM from $M$. avium bound poorly to DC-SIGN since it expresses single mannose residue attachments and thus presents lower mannoside density (Geijtenbeek et al., 2003; Maeda et al., 2003). ManLAM was therefore believed to be the major ligand on M. tuberculosis for binding to DC-SIGN (Maeda et al., 2003; Tailleux et al., 2003). However, later studies showed that removal of the mannose-cap in experiments using whole bacteria did not appear to have a dramatic effect on DC-SIGN binding. The faster growing mycobacteria such as $M$. smegmatis or M. avium could also bind DC-SIGN despite not having the mannose caps, suggesting that other components in the mycobacterial cell wall were also binding DC-SIGN. Mannosylated lipoproteins found on the cell surface of mycobacteria such as $19 \mathrm{kDa}$ lipoprotein IpqH/Rv3763 and a $45 \mathrm{kDa}$ lipoprotein were shown to contribute to the binding of DC-SIGN to the bacteria (Pitarque et al., 2005; Appelmelk et al., 2008). These studies have revealed that the binding interaction of DC-SIGN to $M$. tuberculosis is more complicated than originally perceived, and suggests that there may be more potential DC-SIGN ligands present on $M$. tuberculosis.

In this study we set out to demonstrate DC-SIGN binding to $M$. bovis BCG as a model organism for $M$. tuberculosis. We explored the binding characteristics of DC-SIGN to whole $M$. bovis $\mathrm{BCG}$ and also observed the binding characteristics of a closely related protein, DC-SIGNR (DC-SIGN-Related/LSIGN/CD299) to the mycobacterium. DC-SIGNR shares $77 \%$ amino acid sequence identity with DC-SIGN (Soilleux et al., 2000). Using affinity chromatography, we purified and identified four novel DC-SIGN binding ligands of $M$. bovis BCG: chaperone protein DnaK (DnaK), $60 \mathrm{kDa}$ chaperonin-1 (Cpn60.1), glyceraldehyde-3 phosphate dehydrogenase (GAPDH) and lipoprotein IprG.

\section{RESULTS AND DISCUSSION}

We set out first to confirm the binding of DC-SIGN to whole $M$. bovis BCG, using lung surfactant protein A (SP-A) and BSA as positive and negative controls respectively. We also compared the binding of DC-SIGN to that of DC-SIGNR. By flow cytometry, we found that the binding of DC-SIGN and DC-SIGNR to whole $M$. bovis BCG is dose-dependent (Fig. 1), reaching a maximum at a protein input of about $10 \mu \mathrm{g}$ per $5 \times 10^{8}$ cells (Fig. 2A). SP-A also binds dosedependently, while BSA does not bind. Binding of DC-SIGN and DC-SIGNR are predominantly $\mathrm{Ca}^{2+}$-dependent, as binding is reduced by $\sim 80 \%$ in the presence of EDTA
(Fig. 2B) compared with binding in $5 \mathrm{mM} \mathrm{CaCl}_{2}$. Binding of SP-A appears less dependent on $\mathrm{Ca}^{2+}$ ions, as binding is reduced $<50 \%$ in EDTA. Mannose $(50 \mathrm{mM})$ inhibits the binding of DC-SIGN and SP-A by less than $20 \%$, while binding of DC-SIGNR is reduced by about $70 \%$ (Fig. 2B). These findings are compatible with the view that DC-SIGN, DC-SIGNR and SP-A are all likely to be binding to several bacterial ligands and the results with mannose and EDTA suggest more than one mode of binding. For DC-SIGNR, the results are consistent with its binding mainly $(\sim 80 \%)$ via its calcium-dependent carbohydrate binding site. For DC-SIGN and SP-A, a much smaller proportion (10\%-20\%) of binding may be mediated via these sites, and other binding occurs via $\mathrm{Ca}^{2+}$-independent sites, and also via $\mathrm{Ca}^{2+}$ dependent sites that do not constitute the canonical carbohydrate binding site. Similar diversity for modes of binding of SP-A to viable and apoptotic mammalian cells has been observed previously (Jäkel et al., 2010a, b, c).

To identify macromolecules on the mycobacterial cell surface to which DC-SIGN is binding, M. bovis BCG lysates were passed through a DC-SIGN affinity chromatography column. Bound proteins were eluted with buffer containing EDTA. The eluted proteins were then concentrated and resolved by SDS-PAGE. From the gel (Fig. 3) four visible bands can be seen at $74,60,37$ and $27 \mathrm{kDa}$. As a control $M$. bovis BCG lysates were passed through a control column made of underivatised Sepharose in the same way. No protein was detected in the eluted fractions of the control column, indicating no non-specific binding interactions (not shown). The 74, 60, 37 and $27 \mathrm{kDa}$ bands were cut from the gel and analyzed by MALDI-TOF tryptic peptide fingerprinting mass spectrometry, and database searches carried out against both $\mathrm{NCIBr}$ and SwissProt. The bands were identified as chaperone protein DnaK, $60 \mathrm{kDa}$ chaperonin (Cpn60.1), glyceraldehyde-3-phosphate dehydrogenase (GADPH) and lipoprotein IprG, respectively (Table 1). All of these have the same protein sequence in $M$. tuberculosis as in M. bovis BCG (Table 1). Two other minor candidates, CTP synthase and ATP synthase beta subunit (Table 1) were not considered further.

DnaK and Cpn60.1 are collectively known as heat shock proteins or chaperone proteins. Cpn60.1 generated the highest protein score, with nine peptide sequences matched. These peptide sequences cover $38.51 \%$ of the protein sequence (Table 1). The protein ran at $\sim 60 \mathrm{kDa}$ on a SDSPAGE gel and was calculated to have a mass of $55,877 \mathrm{Da}$ from the amino acid sequence (Fig. 3 and Table 1). The second highest protein score was for DnaK. This protein band produced four matching peptides sequences which contribute $11.2 \%$ sequence coverage. It ran at $\sim 70 \mathrm{kDa}$ on SDS-PAGE and had a calculated mass from the amino acid sequence of 66,830 Da (Fig. 3 and Table 1).

Toward the C-terminal of Cpn60.1, there is one possible Nlinked glycosylation site at $\mathrm{N}^{506} \mathrm{AS}$ (Fig. 4). This potential 

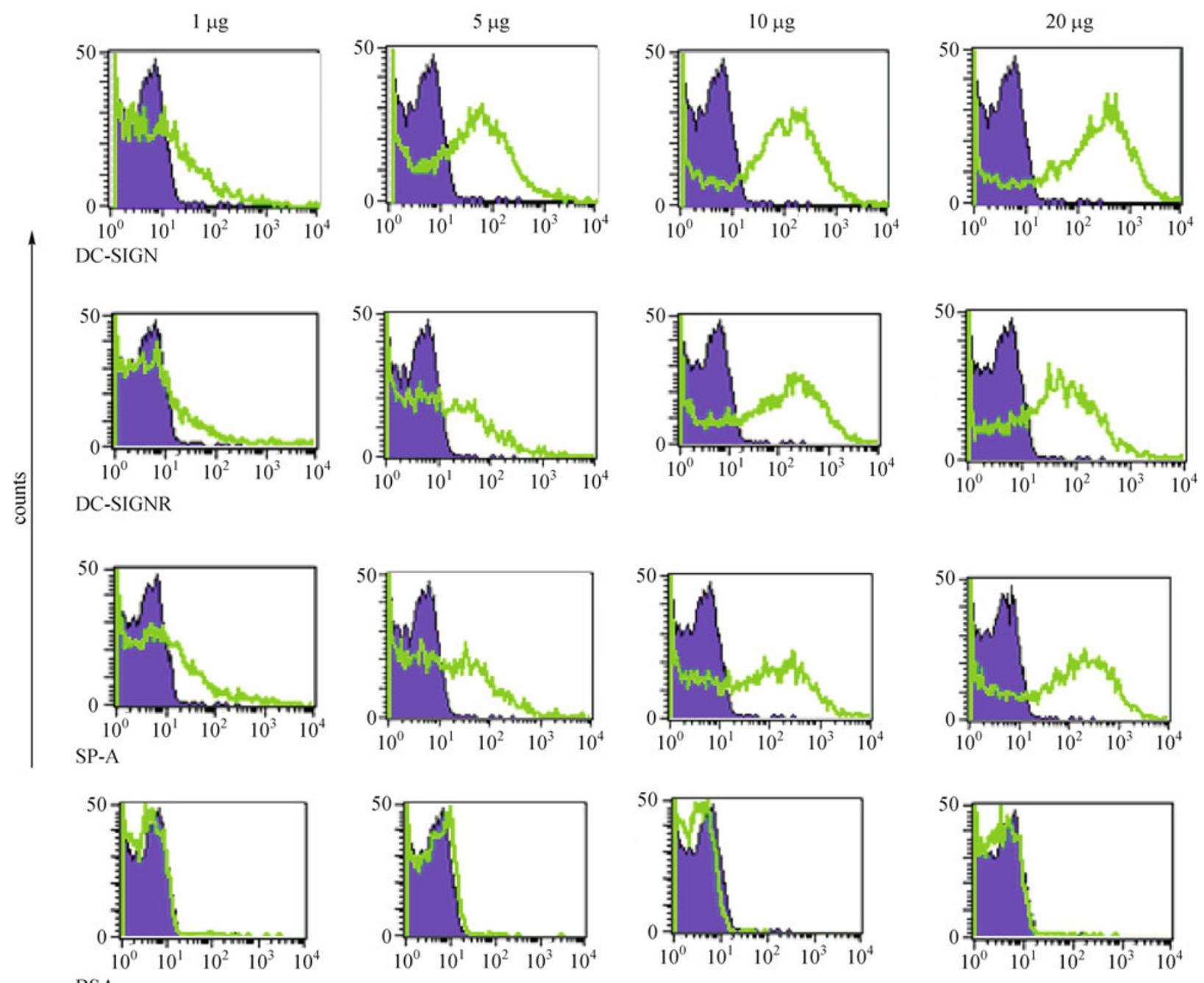

FL2-H

Figure 1. DC-SIGN, DC-SIGNR and SPA bind to whole M. bovis BCG. M. bovis BCG cells were washed in PBS and fixed in paraformaldehyde. Bacteria alone (solid) or bacteria incubated with protein (open) $\left(5 \times 10^{8}\right.$ cells) were incubated with either biotinylated-DC-SIGN, biotinyalted-DC-SIGNR, SP-A or biotinylated-BSA $(1,5,10,20 \mu \mathrm{g}$, respectively). SP-A binding was detected by incubating the cells with a biotinylated monoclonal anti-SPA antibody. All cells were then treated with streptavidin-PE and binding was measured using fluorescent cytometry. Biotinylated-BSA was used as a negative control. Results are representative of three independent experiments.

$\mathrm{N}$-linked glycosylation site occurs in one of the Cpn60.1 peptides identified during mass spectrometry. This indicates that the site was not occupied by an oligosaccharide otherwise the peptide molecular mass would have been affected and unidentifiable during analysis. The site may be partially occupied indicating that there may be another population of this protein with an $\mathrm{N}$-linked glycan present at $\mathrm{N}^{506}$. However, the form of this protein identified after capture by the affinity column was not glycosylated at this position, and it is therefore very unlikely that DC-SIGN binds to this ligand via its $\mathrm{Ca}^{2+}$-dependent lectin activity. Similarly, no potential N-linked glycosylation sites for DnaK were found
(Fig. 4), suggesting that it also is not bound to DC-SIGN via Nglycans. From the current literature it is unknown whether these proteins undergo any O-linked glycosylation, but use of in silico O-glycosylation prediction tools available at the EXPASy (Expert Protein Analysis System) proteomics server (http://expasy.org/tools/; Gasteiger et al., 2003) indicates no predicted O-glycosylation in either protein.

A recent study (Hickey et al., 2009) showed that DnaK is located at the cell-surface of $M$. tuberculosis. There are no published data on the localization of Cpn60.1, but a related protein, Cpn60.2 was also shown to be on the cell surface of $M$. tuberculosis, and has a role in the adherence of $M$. 
A

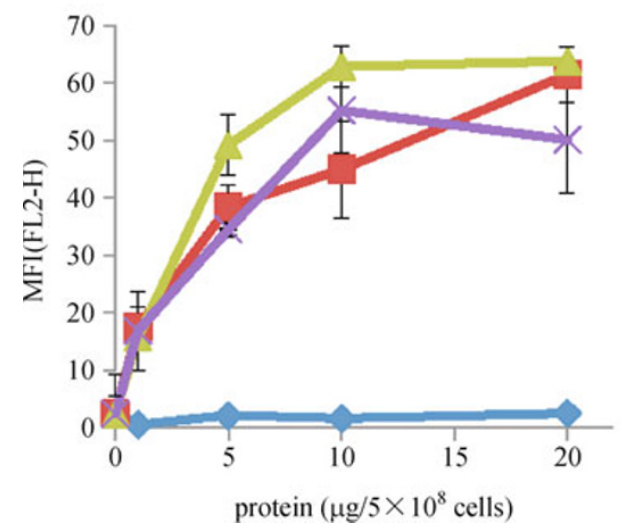

B

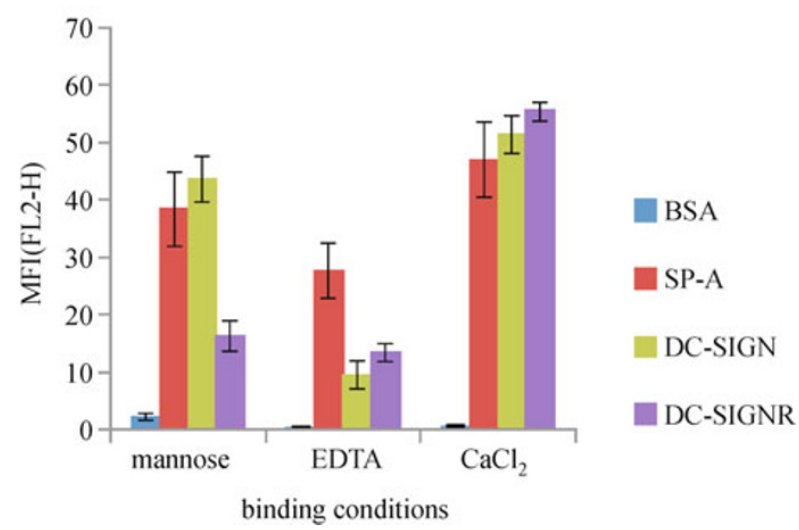

Figure 2. Binding of DC-SIGN, DC-SIGNR and SPA to whole M. bovis BCG. M. bovis BCG cells were washed in PBS and fixed in paraformaldehyde. (A) $5 \times 10^{8}$ cells were incubated with 1, 5, 10, $20 \mu \mathrm{g}$ biotinylated-DC-SIGN, biotinylated-DC-SIGNR, SP-A and biotinylated-BSA in the presence of $5 \mathrm{mM} \mathrm{CaCl}_{2}$. After incubations, SP-A was detected using a biotinylated monoclonal anti-SP-A antibody. Cells were then incubated with streptavidin-PE and binding was measured by flow cytometry. MFI (FL2-H) indicates the mean fluorescent intensity of PE-positive cells. Results are expressed as the mean of three independent experiments \pm SD. (B) $5 \times 10^{8}$ cells were incubated with $20 \mu$ biotinylated-DC-SIGN, biotinylated-DC-SIGNR, SP-A and biotinylated BSA in the presence of $50 \mathrm{mM}$ mannose plus $5 \mathrm{mM} \mathrm{CaCl}_{2}$, or $5 \mathrm{mM}$ EDTA or $5 \mathrm{mM} \mathrm{CaCl}_{2}$ without mannose. Biotinylated-BSA was used as a negative control. Cells were treated as above. Results are expressed as the mean of two independent experiments \pm SD.

tuberculosis to macrophages (Hickey et al., 2009). Cpn60.1 and Cpn60.2 show 61\% amino acid sequence identity (Kong et al., 1993). Hickey et al. (2009) showed that macrophages formed specific interactions with $M$. tuberculosis, which could be inhibited by pre-incubation with increasing concentrations of Cpn60.2 or by blocking surface localized Cpn60.2 with $\mathrm{F}\left(\mathrm{ab} \mathrm{b}^{\prime}\right)_{2}$ antibody. This was supported by showing that purified Cpn60.2 could bind to the surface of macrophages. Although DnaK was also shown to be located at the mycobacterial cellsurface, Hickey et al. (2009) could not show consistent binding via DnaK to macrophages using antibodies to block the reaction. This may have been due to a lack of appropriate anti-DnaK antibodies. In Listeria monocytogenes, DnaK has been shown to facilitate phagocytosis of the pathogen into macrophages (Hanawa et al., 1999). The same authors observed that wild type bacteria were endocytosed more than DnaK knockouts. Once inside the macrophage DnaK was shown not to be essential for multiplication within the cell although it was necessary for cell entry. Studies looking at the pathogenic role of the DnaK and its co-chaperone DnaJ, in Salmonella enterica serovar Typhimurium revealed that they are both essential for internalising the bacteria within epithelial cells and survival within macrophages (Takaya et al., 2004).

Cpn60.1 and Cpn60.2 are potent immunomodulatory proteins in the host. Cpn60.1 has been shown to be a more potent activator of stimulatory proinflammatory cytokines (Friedland et al., 1993; Lewthwaite et al., 2001; Hu et al., 2008). Despite chaperones being more commonly known as cytosolic proteins, many pathogenic bacteria express these proteins at the cell-surface possibly to promote attachment to host cells and mediate internalization. Cpn60 proteins have been reported to demonstrate these functions in Helicobacter pylori, Clostridium difficile, Hemophilus ducreyi and Salmonella enterica serovar Typhimurium (Yamaguchi et al., 1996; Frisk et al., 1998; Hennequin et al., 2001). Here we demonstrate that Cpn60.1 can also interact with DC-SIGN and propose that this could aid the entry of mycobacterial cells into DC or macrophage.

GAPDH was also identified as one of four DC-SIGN binding ligands in this study. Running at $\sim 37 \mathrm{kDa}$ on SDSPAGE (Fig. 3), GAPDH was identified with three peptide matches, covering $15.04 \%$ of the protein sequence. The calculated mass of the protein is $35,955 \mathrm{Da}$ and two potential $\mathrm{N}$-linked glycosylation sites are present in the sequence, $\mathrm{N}^{53} \mathrm{ST}$ and $\mathrm{N}^{154} \mathrm{AS}$ (Table 1, Fig. 4). These two potential $\mathrm{N}$ linked glycosylation sites may be occupied by carbohydrate structures required for DC-SIGN binding via its CRD. This protein has significant homology to the GAPDH enzymes indentified in Group A Streptococcus, enteropathogenic E. coli, and Candida albicans (Parker and Bermudez, 2000). GAPDH is an important enzyme in both prokaryotic and eukaryotic metabolism that catalyzes a step of glycolysis, converting glyceraldehyde-3-phosphate to glycerate 1,3-bisphosphate. GAPDH is more commonly recognized as a cytosolic enzyme found on the inner surface of the cell membrane. Even though there is no apparent signal sequence or stretch of hydrophobic residues to indicate a transmembrane region (Fig. 4), studies have reported that a $37 \mathrm{kDa}$ protein homologous to GAPDH is expressed on the 


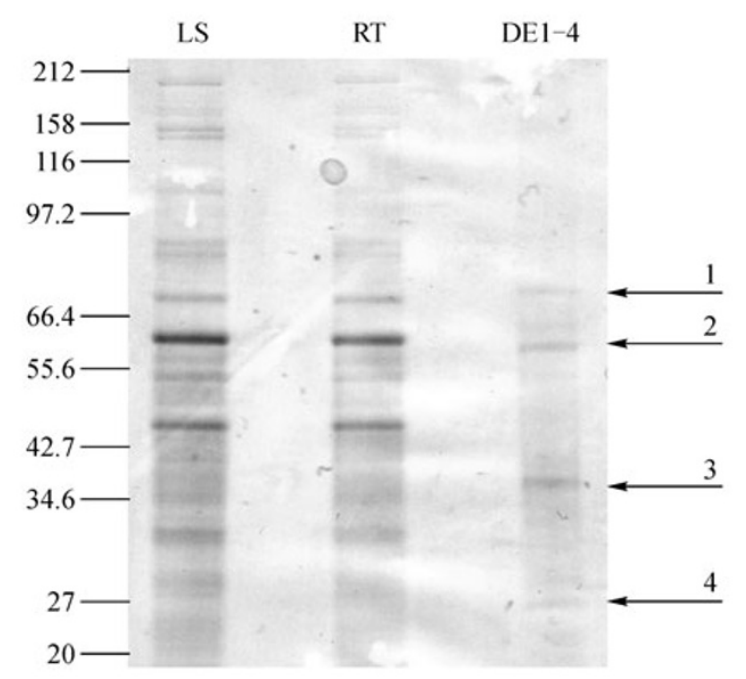

Figure 3. M. bovis BCG lysate proteins binding to immobilised DC-SIGN. DC-SIGN Sepharose was incubated with $M$. bovis BCG lysate in $10 \mathrm{mM}$ Hepes, $140 \mathrm{mM} \mathrm{NaCl}, 5 \mathrm{mM} \mathrm{CaCl}_{2} \mathrm{pH}$ 7.4. The Sepharose was placed in a column and washed and bound proteins were eluted with $10 \mathrm{mM}$ Hepes, $140 \mathrm{mM} \mathrm{NaCl}, 5 \mathrm{mM}$ EDTA pH 7.4. Eluted fractions were concentrated with Strataclean beads and prepared in reducing conditions for analysis by SDS-PAGE. Concentrated eluates were run on $4 \%-12 \%$ gradient gel. As a negative control, underivatised Sepharose was incubated with the lysate in the same way (results not shown). LS, $2 \mu \mathrm{L}$ of $M$. bovis BCG lysate; RT, $2 \mu \mathrm{L}$ lysate proteins not bound to the column ("run-through"); DE1-4, concentrated eluted fractions 1-4 from the DCSIGN column. Bands marked by black arrows were used for mass spectrometry analysis. Results are representative of three independent experiments.

outer cell membrane of hematopoietic cells (Allen et al., 1987) and also on many microorganisms such as Group A Streptococcus, enteropathogenic E. coli, Candida albicans, Mycobacterium avium and Schistosoma mansoni (GoudotCrozel et al., 1989; Pancholi and Fischetti, 1992; Kenny and Finlay, 1995; Gil-Navarro et al., 1997; Parker and Bermudez, 2000). M. avium expresses GAPDH on its cell surface, whereupon GAPDH can bind to human epidermal growth factor. In the presence of recombinant human epidermal growth factor the rate of growth of $M$. tuberculosis and $M$. avium is rapidly increased (Parker and Bermudez, 2000).

Another DC-SIGN ligand purified by affinity chromatography was identified as IprG, a $24 \mathrm{kDa}$ lipoprotein. LprG actually runs with an apparent molecular weight of $27 \mathrm{kDa}$ on SDSPAGE (Fig. 3) and was identified with only one peptide hit with a protein score of 70.07 , covering $7.62 \%$ of the protein sequence. The calculated mass of the protein is $24,547 \mathrm{Da}$ (Fig. 4). The identification of IprG was supported by Western blot analysis. As shown in Fig. 5, in eluted fractions DE1-2, DE3-4 and DE5- 6 from DC-SIGN affinity chromatography, a strong band can be seen representing IprG. LprG has two potential $\mathrm{N}$-linked glycosylation sites, one of which $\left(\mathrm{N}^{83} \mathrm{PT}\right)$ is unoccupied or only partially occupied since it lies in one of the peptides identified by mass spectrometry. The other site, $\mathrm{N}^{185} \mathrm{AT}$ may be occupied. Ligand blot analysis (Fig. 6) of whole $M$. bovis BCG lysate incubated with either ${ }^{125}$ I-DCSIGN or ${ }^{125}$ I-DC-SIGNR revealed that DC-SIGN and DC-
SIGNR both bind the same protein at around $27 \mathrm{kDa}$, which corresponds to IprG in our SDS-PAGE system, and is the only ligand detected by this method. DC-SIGN and DC-SIGNR binding to IprG can therefore still occur when the mycobacterial protein has been denatured by SDS-PAGE. This strongly suggests that IprG binds to DCSIGN predominantly or entirely via protein-carbohydrate interactions.

In other studies looking at the importance of IprG in $M$. tuberculosis, knockout of the IprG operon was shown to attenuate M. tuberculosis, indicating that it has a prominent role in the pathogenic behavior of the bacterium (Bigi et al., 2004). Furthermore, IprG has been identified as a ligand for TLR-2 on macrophages, and IprG-TLR-2 interactions lead to reduced MHC class II presentation (Gehring et al., 2004). There is also growing evidence indicating that intracellular signaling via DC-SIGN modifies transduction pathways downstream from TLRs, driving immunosuppressive responses (Gringhuis et al., 2007, 2009).

Several other M. tuberculosis lipoproteins that are either glycosylated or presumed to be glycosylated also have been identified as key antigens with immunomodulatory functions (Herrmann et al., 2000). LpqH (19 kDa) was confirmed to have seven O-linked glycosylation sites (Herrmann et al., 2000). It has the same protein sequence in $M$. tuberculosis as in $M$. bovis BCG and was previously identified as a ligand for DC-SIGN (Pitarque et al., 2005) possibly binding via glycans. We were unable accurately to detect lipoproteins below 
Table 1 Peptide hits of proteins eluted from DC-SIGN affinity chromatography

\begin{tabular}{lccccc}
\hline band & molecular & protein name & peptide sequence & protein score & calculated \\
No. & weight $(\mathrm{kDa})$ & & & occurrence
\end{tabular}

(Fig. 3) (SDS-PAGE)

\begin{tabular}{|c|c|c|c|c|c|c|}
\hline 1 & 74 & $\begin{array}{c}\text { chaperone } \\
\text { protein dnaK }\end{array}$ & $\begin{array}{l}4 \text { peptides matched: } \\
\text { LLGSFELTGIPPAPR, } \\
\text { DVLLLDVTPLSLGIETK, } \\
\text { IQEGSGLSKEDIDR, } \\
\text { GVNPDEVVAVGAAL- } \\
\text { QAGVLKGEVK, } 11.2 \% \\
\text { sequence coverage }\end{array}$ & 120.7 & 66.83 & $\begin{array}{c}\text { Mycobacterium bovis BCG } \\
\text { (Pasteur 1173P2), } \\
\text { Mycobacterium bovis, } \\
\text { Mycobacterium tuberculosis }\end{array}$ \\
\hline 1 & 74 & CTP synthase & $\begin{array}{l}1 \text { peptide matched: } \\
\text { GLTASSLGQLLTAR, } 2.38 \% \\
\text { sequence coverage }\end{array}$ & 52.86 & 63.635 & $\begin{array}{c}\text { Mycobacterium bovis BCG } \\
\text { (Pasteur 1173P2), } \\
\text { Mycobacterium bovis, } \\
\text { Mycobacterium tuberculosis }\end{array}$ \\
\hline 2 & 60 & $\begin{array}{c}60 \mathrm{kDa} \\
\text { chaperonin } 1\end{array}$ & $\begin{array}{c}9 \text { peptides matched: } \\
\text { AADAVSEALLASATPVSGK, } \\
\text { AFGGPTVTNDGVTVAR, } \\
\text { LVAAGVNPIALGVGIGK, } \\
\text { AAVEEGIVPGGGASLIHQAR, } \\
\text { SAVLNASSVAR, } \\
\text { EVGLEVLGSAR, } \\
\text { AMEVGMDKLADTVR, } \\
\text { ESVEDAVAAAK, } \\
\text { TGIAQVATVSSRDEQIGDLV- } \\
\text { GEAMSK, } 26.90 \% \text { sequence } \\
\text { coverage }\end{array}$ & 409.71 & 55.877 & $\begin{array}{c}\text { Mycobacterium bovis BCG } \\
\text { (Pasteur 1173P2), } \\
\text { Mycobacterium bovis, } \\
\text { Mycobacterium tuberculosis }\end{array}$ \\
\hline 2 & 60 & $\begin{array}{l}\text { ATP synthase } \\
\text { beta-subunit }\end{array}$ & $\begin{array}{l}1 \text { peptide matched: } \\
\text { TISLQPTDGLVR, } 2.46 \% \\
\text { sequence coverage }\end{array}$ & 27.99 & 53.094 & $\begin{array}{c}\text { Mycobacterium bovis BCG } \\
\text { (Pasteur 1173P2), } \\
\text { Mycobacterium bovis, } \\
\text { Mycobacterium tuberculosis }\end{array}$ \\
\hline 3 & 37 & $\begin{array}{l}\text { glyceraldehyde- } \\
\text { 3-phosphate } \\
\text { dehydrogenase }\end{array}$ & $\begin{array}{l}3 \text { peptides matched: } \\
\text { LVDLVTLVGK, } \\
\text { AAALNIVPTSTGAAK, } \\
\text { YYDAPIVSSDIVTDPHS- } \\
\text { SIFDSGLTK, } 15.04 \% \\
\text { sequence coverage }\end{array}$ & 65.65 & 35.955 & $\begin{array}{c}\text { Mycobacterium bovis BCG } \\
\text { (Pasteur 1173P2), } \\
\text { Mycobacterium bovis, } \\
\text { Mycobacterium tuberculosis }\end{array}$ \\
\hline 4 & 27 & $\begin{array}{l}\text { lipoprotein IprG } \\
\text { precursor }\end{array}$ & $\begin{array}{l}1 \text { peptide matched: } \\
\text { TLSGDLTTNPTAATGNVK, } \\
7.62 \% \text { sequence coverage }\end{array}$ & 70.07 & 24.547 & $\begin{array}{c}\text { Mycobacterium bovis BCG } \\
\text { (Pasteur 1173P2), } \\
\text { Mycobacterium bovis, } \\
\text { Mycobacterium tuberculosis }\end{array}$ \\
\hline
\end{tabular}

$20 \mathrm{kDa}$ in the affinity chromatography experiment shown in Fig. 3 due to limitations in the SDS-PAGE system used, but in Fig. 6 (ligand blotting) no band in the position of IpqH is seen. This suggests either that IprG is a much better ligand (more abundant or higher affinity) or that $\mathrm{IpqH}$ does not bind via glycans.

LprG binds to both DC-SIGN and DC-SIGNR. DC-SIGNR is expressed in the liver, lymph nodes but has also been described in the lung (Pöhlmann et al., 2001; Jeffers et al., 2004). In humans, both DCs and alveolar macrophages express DC-SIGN in the lungs. Although DC-SIGNR has a different expression pattern from DC-SIGN, it has similar binding properties to DC-SIGN (Bashirova et al., 2001;
Mitchell et al., 2001; Pöhlmann et al., 2001). While DCSIGN has been shown to mediate endocytosis and protein trafficking as a recycling receptor and the release of bound ligand at reduced $\mathrm{pH}$, DC-SIGNR does not endocytose nor demonstrate $\mathrm{pH}$-sensitive ligand binding (Guo et al., 2004).

DC-SIGN has been implicated as an important receptor in the establishment of $M$. tuberculosis infection. Although many DC-SIGN ligands have been identified at the cell-surface of the mycobacterium, studies suggested that there were more ligands present that had not yet been identified. Here, we have shown DC-SIGN binds to whole $M$. bovis BCG in both $\mathrm{Ca}^{2+}$-dependent and $\mathrm{Ca}^{2+}$-independent modes. We have identified four novel ligands for DC-SIGN. Of these only one, 
A HEAT SHOCK PROTEIN 7OKDA/CHAPERONE PROTEIN DNAK (DNAK)

1 - MARAVGIDLG TTNSVVSVLE GGDPVVVANS EGSRTTPSIV AFARNGEVLV GQPAKNQAVT

61 - NVDRTVRSVK RHMGSDWSIE IDGKKYTAPE ISARILMKLK RDAEAYLGED ITDAVITTPA

121 - YFNDAQRQAT KDAGQIAGLN VLRIVNEPTA AALAYGLDKG EKEQRILVFD LGGGTFDVSL

181 - LEIGEGVVEV RATSGDNHLG GDDWDQRVVD WLVDKFKGTS GIDLTKDKMA MQRLREAAEK

241 - AKIELSSSQS TSINLPYITV DADKNPLFLD EQLTRAEFQR ITQDLLDRTR KPFQSVIADT

301 - GISVSEIDHV VLVGGSTRMP AVTDLVKELT GGKEPNKGVN PDEVVAVGAA LQAGVLKGEV

361 - KDVLILDVTP LSLGIETKGG VMTRLIERNT TIPTKRSETF TTADDNQPSV QIQVYQGERE

421 - IAAHNKLLGS FELTGIPPAP RGIPQIEVTF DIDANGIVHV TAKDKGTGKE NTIRIQEGSG

481 - LSKEDIDRMI KDAEAHAEED RKRREEADVR NQAETLVYQT EKFVKEQREA EGGSKVPEDT

541 - LNKVDAAVAE AKAALGGSDI SAIKSAMEKL GQESQALGQA IYEAAQAASQ ATGAAHPGGE

601 - PGGAHPGSAD DVVDAEVVDD GREAK

B PROTEIN CPN60.1 (GROEL PROTEIN 1)

1 - MSKLIEYDET ARRAMEVGMD KLADTVRVTL GPRGRHVVLA KAFGGPTVTN DGVTIVAREIE

61 - LEDPEEDLGA QLVKSVATKT NDVAGDGTTT ATILAQALIK GGLRLVAAGV NPIALGVGIG

121 - KAADAVSEAL ILASATPVSGK TGIAQVATVS SRDEQIGDLV GEAMSKVGHD GVVSVEESST

181 - LGTELEFTEG IGFDKGFLSA YFVTDFDNQQ AVLEDALILL HQDKISSLPD LLPLLEKVAG

241 - TGKPLIIVAE DVEGEALATL VVNAIRKTLK AVAVKGPYFG DRRKAFLEDL AVVTGGQVVN

301 - PDAGMVLREV GLEVLGSARR VVVSKDDTVI VDGGGTAEAV ANRAKHLRAE IDKSDSDWDR

361 - EKLGERLAKL AGGVAVIKVG AATETALKER KESVEDAVAA AKAAVEEGIV PGGGASLIHQ

421 - ARKALTELRA SLTGDEVLGV DVFSEALAAP LFWIAANAGL DGSVVVNKVS ELPAGHGLNV

481 - NTLSYGDLAA DGVIDPVKVT RSAVLNASSV ARMVLTTETV VVDKPAKAED HDHHHGHAH

C PROBABLE GLYCERALDEHYdE 3-PHOSPHATE DEHYdROGENASE (GAP/GAPDH)

1 - VTVRVGINGF GRIGRNEYRA LLAQQEQGTA DVEVVAANDI TDNSTLAHLL KEDSILGRLP

61 - CDVGLEGDDT IVVGRAKIKA LAVREGPAAL PWGDLGVDVV VESTGLFTNA AKAKGHLDAG

121 - AKKVIISAPA TDEDITIVLG VNDDKYDGSQ NIISNASCTT NCLAPLAKVL DDEFGIVKGL

181 - MTTIHAYTQD QNLQDGPHKD LRRARAAALN IVPTSTGAAK AIGLVMPQLK GKLDGYALRV

241 - PIPTGSVTDL TVDLSTRASV DEINAAFKAA AEGRLKGILK YYDAPIVSSD IVIDPHSSIF

301 - DSGLTKVIDD QAKVVSWYDN EWGYSNRLVD LVTLVGKSL

D PROBABLE CONSERVED LIPOPROTEIN LPRG (LPRG)

1 - MRTPRRHCRR IAVLAAVSIA ATVVAGCSSG SKPSGGPLPD AKPLVEEATA QTKALKSAHM

61 - VLTVNGKIPG LSLKTLSGDL TTNPTAATGN VKLTLGGSDI DADEVVEDGI LYATLTPNQW

121 - SDFGPAADIY DPAQVLNPDT GLANVLANEA DAKAEGRDTI NGQNTIRISG KVSAQAVNQI

181 - APPENATQPV PATVWIQETG DHQLAQAQLD RGSGNSVQMT LSKWGEKVQV TKPPVS

Figure 4. Protein sequences of the identified eluted proteins. Protein sequences of the four identified proteins eluted from DCSIGN affinity chromatography. (A) Chaperone protein DnaK (DnaK), (B) chaperone protein 60 (Cpn60.1), (C) glyceraldehyde 3phosphate dehydrogenase (GADPH), and (D) lipoprotein IprG (IprG). In red, peptides identified by MS-MS, and in purple, potential Nlinked glycosylation sites. Sequences were obtained from databases as described in the text.

IprG appears to bind predominantly via the glycan binding site. LprG is also a ligand for DC-SIGNR. Dendritic cells present in the lung migrate in order to prime T lymphocytes in the lymph nodes. It is believed that $M$. tuberculosis resides within the phagosome of the DC and exploits the migration thereby circulating within the host undetected (Fenton and
Vermeulen, 1996; Henderson et al., 1997; Banchereau and Steinman, 1998). The discovery of new DC-SIGN binding ligands: DnaK, Cpn60.1, GAPDH and IprG, may help further research into designing inhibitors to prevent interactions between DC-SIGN and M. tuberculosis with the aim of blocking uptake and intracellular survival of mycobacterial cells. 


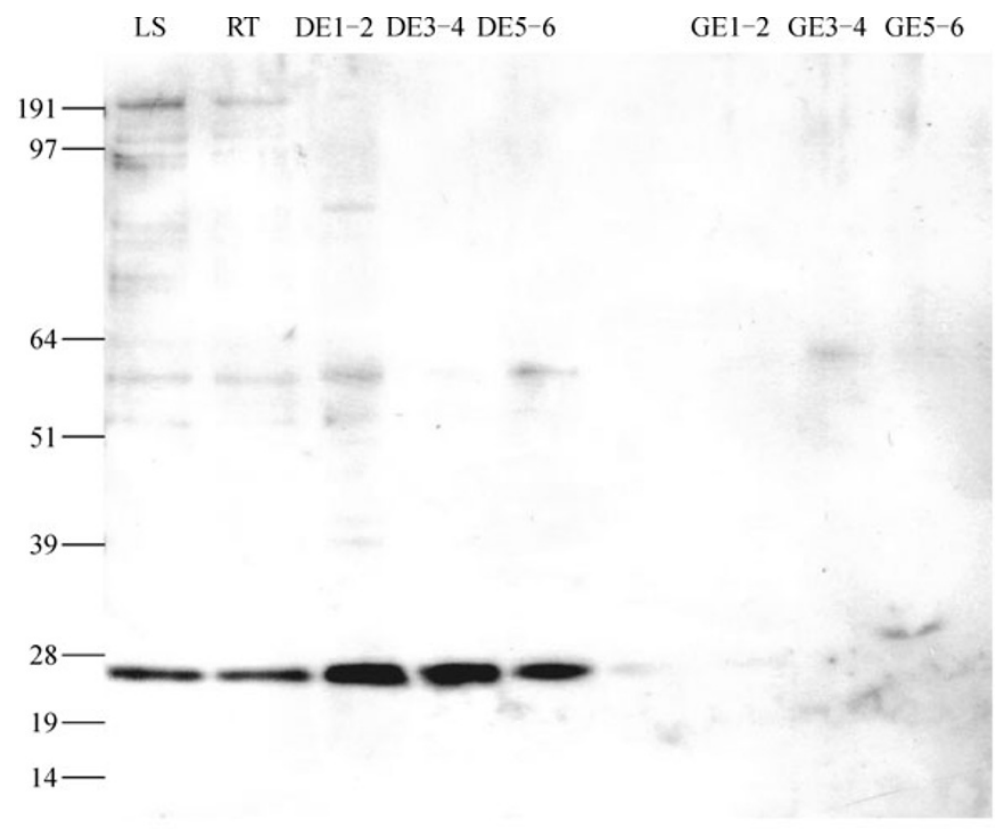

Figure 5. Western blot confirmation of IprG binding to DC-SIGN-Sepharose. SDS-PAGE of concentrated eluted fractions were transferred to a PVDF membrane and blocked. The membrane was incubated with rabbit anti-lprG antiserum, then washed and incubated with goat anti-rabbit-horseradish peroxidase (HRP)-conjugated antibody. The membrane was washed and exposed to Enhanced Chemiluminescence Western Blot Detection Reagents. The bands were visualized by exposing the membrane to Xray film for a few seconds. Results are representative of 2 independent experiments. LS, lysate; RT, run-through; DE1-6, eluted fractions from the DC-SIGN column; GE1-6, eluted fractions from the guard (underivatised Sepharose) column.

\section{MATERIALS AND METHODS}

\section{Mycobacterial cultures}

Liquid cultures of Mycobacterium bovis BCG (Pasteur strain) were grown as described previously (Carroll et al., 2009) in Middlebrook $7 \mathrm{H} 9$ liquid medium containing $0.2 \%(\mathrm{v} / \mathrm{V})$ glycerol, $0.05 \%(\mathrm{v} / \mathrm{V})$ Tween80 , and $10 \%(v / v)$ albumin-dextrose-catalase (ADC, BD BBL Prepared Culture Medium: Becton Dickinson, Oxford, UK). Fresh cultures were inoculated from $1 \mathrm{~mL}$ glycerol stock of $M$. bovis BCG to generate a $100 \mathrm{~mL}$ culture. The 'first passage' was grown for four to five days at $37^{\circ} \mathrm{C}$ in roller bottles at $2 \mathrm{rpm}$ until the bacteria had reached the exponential growth phase $\left(\mathrm{OD}_{600 \mathrm{~nm}}=0.80-1.00\right)$. Only the first passages of the strains were used for experimental work.

\section{Preparation of cell lytates}

M. bovis BCG cell cultures $(200 \mathrm{~mL})$ were harvested at exponential phase and cells were washed three times in $137 \mathrm{mM} \mathrm{NaCl}, 2.6 \mathrm{mM}$ $\mathrm{KCl}, 8.2 \mathrm{mM} \mathrm{Na}_{2} \mathrm{HPO}_{4}$ and $1.5 \mathrm{mM} \mathrm{KH}_{2} \mathrm{PO}_{4}, \mathrm{pH} 7.4$ (PBS). Cells were resuspended in $3 \mathrm{~mL} 10 \mathrm{mM}$ Tris, $140 \mathrm{mM} \mathrm{NaCl}, 0.5 \%$ Triton $\mathrm{X}-100, \mathrm{pH} 7.5$ in the presence of protease inhibitors (Protease Inhibitor Cocktail, Roche Diagnostics, Mannheim Germany) and kept on ice for $5 \mathrm{~min}$. The cells were then ribolysed in ribolysing tubes containing Lysing Matrix B (MPBiomedicals, Illkirch, France) for $45 \mathrm{~s}$ at speed setting 6.5 in a ribolyser (FastPrep FP120). Lysate was placed on ice for $5 \mathrm{~min}$ before being spun down. To reduce viscosity, mycobacterial lysate was incubated with $10 \mu \mathrm{g} / \mathrm{mL}$ of RNase A
(R4642 Sigma Aldrich,Poole UK) for $30 \mathrm{~min}$ at $37^{\circ} \mathrm{C}$. Lysate buffer was adjusted to $2.5 \mathrm{mM} \mathrm{CaCl}_{2}, 2.5 \mathrm{mM} \mathrm{MgCl}_{2}$ and incubated with $10 \mu \mathrm{g} / \mathrm{mL}$ DNase II (D4138, Sigma Aldrich) for $30 \mathrm{~min}$ at $37^{\circ} \mathrm{C}$. The lysate was then stored at $-20^{\circ} \mathrm{C}$ until needed.

\section{Protein Preparations}

Recombinant, tetrameric DC-SIGN and DC-SIGNR (complete extracellular domains, lacking the transmembrane segment) were made and purified as described previously (Mitchell et al., 2001). These were used in either unmodified, biotinylated or radioiodinated form. Biotinylation was performed using N-hydroxysuccinimide biotin (Sigma-Aldrich, Poole, UK) at a molar ratio of 20:1 reagent : protein at $\mathrm{pH} 8.4,4^{\circ} \mathrm{C}$ for $60 \mathrm{~min}$. Radioiodination was done as a standard iodogen-catalyzed reaction (Krarup et al., 2007) with $50 \mu \mathrm{g}$ of protein in PBS and $250 \mathrm{uCi}$ of $\mathrm{Na}^{125}$ (GE Healthcare, UK, product IMS-30). SP-A was purified from human alveolar proteinosis broncho-alveolar lavage fluid as described by Jäkel et al. (2010a).

\section{Flow cytometry}

M. bovis BCG $\left(5 \times 10^{8}\right.$ cells $)$ were fixed in $1.5 \%$ paraformaldehyde in PBS, $2 \mathrm{mM} \mathrm{CaCl}_{2}$. Cells were washed in $100 \mu \mathrm{L} 10 \mathrm{mM}$ Hepes, $140 \mathrm{mM} \mathrm{NaCl}, 5 \mathrm{mM} \mathrm{CaCl}_{2}, \mathrm{pH} 7.4$ (assay buffer) and resuspended in $150 \mu \mathrm{L}$ of the same buffer. Cells were incubated with $0,5,10,20 \mu \mathrm{g}$ of biotinylated-DC-SIGN or biotinylated-DC-SIGNR for $1 \mathrm{~h}$ at room temperature in assay buffer. Incubations were also carried out in the presence of $50 \mathrm{mM}$ mannose and $5 \mathrm{mM}$ EDTA as potential inhibitors 


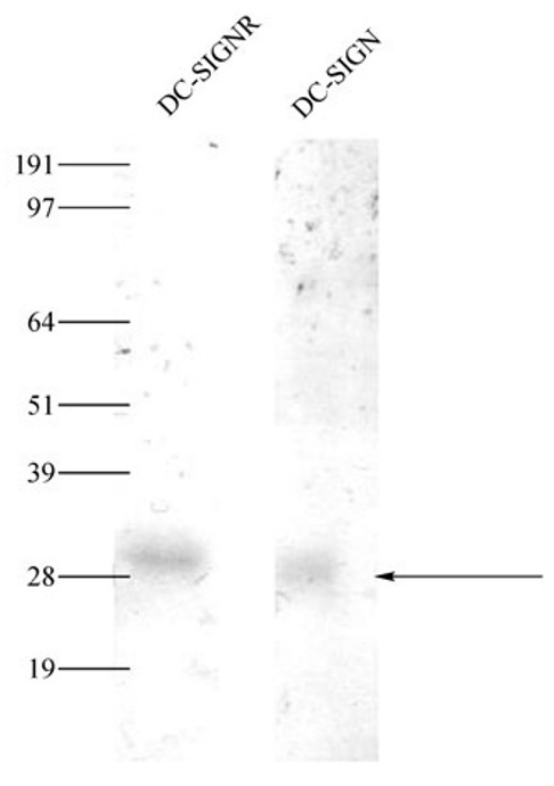

Figure 6. Radiolabelled DC-SIGN and DC-SIGNR binding to $M$. bovis BCG blot. SDS-PAGE of $M$. bovis BCG lysate was run and protein bandswere transferred to a PVDF membrane, blocked and incubated with $15 \mathrm{~mL}$ of $350,000 \mathrm{dpm} / \mathrm{mL}$ of either ${ }^{125}$ I-DC-SIGN or ${ }^{125}$ I-DC-SIGNR. The bands were then visualized by exposing the membrane to X-ray film for 1 week.

of binding to $M$. bovis BCG. Cells were washed and incubated with 1:200 dilution of Streptavidin-PE solution (554061 BD Pharmingen, Oxford, UK) for $40 \mathrm{~min}$ in $100 \mu \mathrm{L}$ assay buffer and fixed in $180 \mu \mathrm{L}$ of $1.5 \%$ paraformaldehyde in $\mathrm{PBS}, 2 \mathrm{mM} \mathrm{CaCl}_{2}$. Binding to the cells was measured by flow cytometry using a FACScan instrument (Becton Dickinson Immunocytometry Systems, San Jose, CA, USA). Aquisition and processing of data from 10,000 cells per sample were carried out with the CellQuest software (Becton Dickinson). Surfactant protein-A (SP-A) was used as positive control (Downing et al., 1995; Pasula et al., 1997; Weikert et al., 1997) and was detected using a biotinylated anti-SP-A monoclonal antibody (AntibodyShop, Gentofte, Denmark); biotinylated BSA was used as a negative control for binding to $M$. bovis BCG.

\section{DC-SIGN Sepharose}

Soluble recombinant DC-SIGN extracellular domain protein $(2 \mathrm{~mL}$, $1 \mathrm{mg} / \mathrm{mL}$ ) in $10 \mathrm{mM}$ Hepes, $140 \mathrm{mM} \mathrm{NaCl}, 5 \mathrm{mM} \mathrm{CaCl} 2, \mathrm{pH} 7.5$ was incubated with $1 \mathrm{~mL}$ hydrated CNBr-activated Sepharose (GE Healthcare, Chalfont St. Giles, UK) for $2 \mathrm{~h}$ at room temperature with rotation. The resin was washed twice in $1 \mathrm{M} \mathrm{NaCl}$ and then incubated in $3 \mathrm{~mL} 100 \mathrm{mM}$ ethanolamine, $\mathrm{pH} 8.8$ for $2 \mathrm{~h}$ at room temperature with rotation. The resin was washed twice in $1 \mathrm{M} \mathrm{NaCl}$ and stored in $25 \mathrm{mM}$ Hepes, $150 \mathrm{mM} \mathrm{NaCl}, 5 \mathrm{mM}$ EDTA, pH 7.5. Fifteen percent of the DC-SIGN supplied remained unbound, as assessed by measuring protein $\mathrm{OD}_{280}$ in the supernatant after binding.

\section{DC-SIGN affinity chromatography}

Capacity of the DC-SIGN-Sepharose for capturing glycoprotein ligand was confirmed using a test solution containing $100 \mu \mathrm{g}$ of yeast invertase ( $20 \%$ oligomannose by mass) loaded onto the column in $1 \mathrm{~mL}$ of $10 \mathrm{mM}$ Hepes, $140 \mathrm{mM} \mathrm{NaCl}, 5 \mathrm{mM} \mathrm{CaCl}_{2} \mathrm{pH} 7.4$ (equilibration buffer) and eluted with $10 \mathrm{mM}$ Hepes, $140 \mathrm{mM} \mathrm{NaCl}$, 5 mM EDTA pH 7.4 (eluting buffer). Successful capture and elution of ligand was visualized by SDS-PAGE. The DC-SIGN-Sepharose column was regenerated with $20 \mathrm{mM}$ Hepes, $2 \mathrm{M} \mathrm{NaCl}, 10 \mathrm{mM}$ EDTA $\mathrm{pH} 7.4$ (regeneration buffer). The column was then equilibrated with equilibration buffer. Lysate treated with RNase and DNase was diluted with one volume of $20 \mathrm{mM}$ Hepes, $140 \mathrm{mM} \mathrm{NaCl}, 7.5 \mathrm{mM}$ $\mathrm{CaCl}_{2}, \mathrm{pH} 7.5$ to obtain $5 \mathrm{~mL}$ with a protein concentration of about $5 \mathrm{mg} / \mathrm{mL}$. As a control, a second column $(1 \mathrm{~mL})$ was made from underivatised Sepharose (guard column) and prepared in equilibration buffer. Lysate $(5 \mathrm{~mL})$ was added to the guard column and the beads were stirred at intervals during an incubation period of $2 \mathrm{~h}$ at $4^{\circ} \mathrm{C}$. The lysate was then run off and loaded onto the DC-SIGN column. Beads were resuspended and incubated with the lysate as above. Both columns were washed exhaustively with equilibration buffer. Bound ligands were eluted with eluting buffer and $0.5 \mathrm{~mL}$ fractions collected. Eluted proteins were detected by reading $\mathrm{OD}_{280}$, and positive fractions were pooled and the protein concentrated by binding to $40 \mu \mathrm{L}$ Strataclean beads (Stratagene, Cedar Creek, TX, USA) per $\mathrm{mL}$ of eluted fraction. Beads were incubated with eluates on a rotary stirrer for $2 \mathrm{~h}$. Beads were spun down and prepared for analysis by SDS-PAGE.

\section{SDS-PAGE}

SDS-PAGE was performed using the Invitrogen NUPAGE $®$ system (Invitrogen, Cambridge, UK). Samples were prepared as described by Fairbanks et al. (1971). A total of $20 \mu \mathrm{L}$ Strataclean beads per concentrated fraction were prepared in reducing conditions for SDSPAGE and loaded per well.

\section{Western blotting}

SDS-PAGE was run with SeeBlue ${ }^{\circledR}$ Plus2 Prestained Standard (Invitrogen) to facilitate band size estimation. Protein bands were transferred to a polyvinylidene fluoride (PVDF) microporous membrane (Millipore, Billerica, Massachusetts, USA) in $48 \mathrm{mM}$ Tris- $\mathrm{HCl}$, $39 \mathrm{mM}$ glycine, 20\% ( $\mathrm{V} / \mathrm{V})$ methanol, $\mathrm{pH} 8.3$ (transfer buffer) for $4 \mathrm{~h}$ using a semi-dry blotter (Whatman International Ltd. Banbury, UK). The membrane was blocked with PBS, $0.2 \%$ Tween- $20,1 \mathrm{mg} / \mathrm{mL}$ BSA for $2 \mathrm{~h}$. The membrane was washed with PBS, $0.2 \%$ Tween-20, $0.5 \mathrm{mM}$ EDTA (washing buffer) and incubated with 1:300 dilution of rabbit anti-IprG antiserum (Bigi et al., 1997) in PBS, $1 \mathrm{mg} / \mathrm{mL}$ BSA for $3 \mathrm{~h}$ at room temperature. The membrane was washed in washing buffer and incubated with 1:10,000 dilution goat anti-rabbit-horseradish peroxidase-conjugated antibody (Sigma Aldrich, A0545) in PBS, $1 \mathrm{mg} / \mathrm{mL}$ BSA for $1 \mathrm{~h}$. The membrane was washed in washing buffer and exposed to Enhanced Chemiluminescence Western Blot Detection Reagents (GE Healthcare) for detection. Bands were detected by exposing the membrane to X-ray film.

\section{Ligand blotting}

SDS-PAGE of reduced $M$. bovis BCG lysate was run and protein bands were transferred to a PVDF microporous membrane and blocked as above. The membrane was washed with $25 \mathrm{mM}$ Hepes, 
$150 \mathrm{mM} \mathrm{NaCl}, 5 \mathrm{mM} \mathrm{CaCl}_{2}, 0.02 \%$ Tween-20 pH 7.4 and incubated with $15 \mathrm{~mL}$ of $350,000 \mathrm{dpm} / \mathrm{mL}$ of either ${ }^{125}$ I-DC-SIGN or ${ }^{125}$ I-DCSIGNR for $2 \mathrm{~h}$ at room temperature. The membrane was washed with $25 \mathrm{mM}$ Hepes, $150 \mathrm{mM} \mathrm{NaCl}, 5 \mathrm{mM} \mathrm{CaCl}_{2}, 0.02 \%$ Tween-20 pH 7.4 and bands were visualized by exposing the membrane to $\mathrm{X}$-ray film in a lightproof cassette for 1 week.

\section{Mass spectrometry}

Protein bands from SDS-PAGE gels were stained with either SafeStain (Invitrogen) or Coomassie Blue R-250 stain (Fairbanks et al., 1971) and destained in 10\% ( $/ / \mathrm{V})$ acetic acid, $10 \%(\mathrm{~V} / \mathrm{V})$ ethanol. Individual bands were excised and subjected to MS-MS analysis. Mass spectrometric analysis was carried out using a Q-TOF 1 (Micromass, Manchester, UK) coupled to a CapLC (Waters, Milford, USA). In-gel trypsin digestion was carried out as described by Shevchenko et al. (2006). Tryptic peptides were concentrated and desalted on a $300 \mu \mathrm{m} \mathrm{id} / 5 \mathrm{mM} \mathrm{C} 18$ pre-column and resolved on a $75 \mu \mathrm{m}$ id/25 cm C18 PepMap analytical column (LC packings, San Francisco, CA, USA). Peptides were eluted to the mass spectrometer using a $45 \mathrm{~min} 5 \%-95 \%(\mathrm{~V} / \mathrm{V})$ acetonitrile gradient containing $0.1 \%$ $(\mathrm{v} / \mathrm{V})$ formic acid at a flow rate of $200 \mathrm{~nL} / \mathrm{min}$. Spectra were acquired in positive mode with a cone voltage of $40 \mathrm{~V}$ and a capillary voltage of $3300 \mathrm{~V}$. The MS to MS/MS switching was controlled in an automatic data-dependent fashion with a $1 \mathrm{~s}$ survey scan followed by three $1 \mathrm{~s}$ MS/MS scans of the most intense ions. Precursor ions selected for MS/MS were excluded from further fragmentation for $2 \mathrm{~min}$. Spectra were processed using ProteinLynx Global Server 2.1.5 and searched against the SwissProt_55.6 and NCBInr_20080718 databases using the MASCOT search engine (Matrix Science, London, UK). Database searches were performed with the taxonomy restricted to Mycobacteria. Carbamidomethyl cysteine was set as a fixed modification and oxidised methionine as a potential variable modification. Data was searched allowing 0.1 Da error on all spectra and up to one missed tryptic cleavage site.

\section{ABBREVIATIONS}

Cpn60.1, 60 kDa chaperonin-1; DC, dendritic cell; DC-SIGN/CD209, dendritic-cell-specific intercellular adhesion molecule-3-grabbing non-integrin; GAPDH, glyceraldehyde-3-phosphate dehydrogenase

\section{REFERENCES}

Allen, R.W., Trach, K.A., and Hoch, J.A. (1987). Identification of the 37-kDa protein displaying a variable interaction with the erythroid cell membrane as glyceraldehyde-3-phosphate dehydrogenase. J Biol Chem 262, 649-653.

Appelmelk, B.J., van Die, I., van Vliet, S.J., Vandenbroucke-Grauls, C.M., Geijtenbeek, T.B., and van Kooyk, Y. (2003). Cutting edge: carbohydrate profiling identifies new pathogens that interact with dendritic cell-specific ICAM-3-grabbing nonintegrin on dendritic cells. J Immunol 170, 1635-1639.

Appelmelk, B.J., den Dunnen, J., Driessen, N.N., Ummels, R., Pak, M., Nigou, J., Larrouy-Maumus, G., Gurcha, S.S., Movahedzadeh, F., Geurtsen, J., et al. (2008). The mannose cap of mycobacterial lipoarabinomannan does not dominate the Mycobacterium-host interaction. Cell Microbiol 10, 930-944.

Armstrong, J.A., and Hart, P.D. (1975). Phagosome-lysosome interactions in cultured macrophages infected with virulent tubercle bacilli. Reversal of the usual nonfusion pattern and observations on bacterial survival. J Exp Med 142, 1-16.

Banchereau, J., and Steinman, R.M. (1998). Dendritic cells and the control of immunity. Nature 392, 245-252.

Bashirova, A.A., Geijtenbeek, T.B., van Duijnhoven, G.C., van Vliet, S.J., Eilering, J.B., Martin, M.P., Wu, L., Martin, T.D., Viebig, N., Knolle, P.A., et al. (2001). A dendritic cell-specific intercellular adhesion molecule 3-grabbing nonintegrin (DC-SIGN)-related protein is highly expressed on human liver sinusoidal endothelial cells and promotes HIV-1 infection. J Exp Med 193, 671-678.

Bigi, F., Espitia, C., Alito, A., Zumarraga, M., Romano, M.I., Cravero, S., and Cataldi, A. (1997). A novel $27 \mathrm{kDa}$ lipoprotein antigen from Mycobacterium bovis. Microbiology 143, 3599-3605.

Bigi, F., Gioffré, A., Klepp, L., Santangelo, M.P., Alito, A., Caimi, K., Meikle, V., Zumárraga, M., Taboga, O., Romano, M.I., et al. (2004). The knockout of the IprG-Rv1410 operon produces strong attenuation of Mycobacterium tuberculosis. Microbes Infect 6, 182-187.

Carroll, M.V., Lack, N., Sim, E., Krarup, A., and Sim, R.B. (2009). Multiple routes of complement activation by Mycobacterium bovis BCG. Mol Immunol 46, 3367-3378.

Clemens, D.L., and Horwitz, M.A. (1995). Characterization of the Mycobacterium tuberculosis phagosome and evidence that phagosomal maturation is inhibited. J Exp Med 181, 257-270.

Downing, J.F., Pasula, R., Wright, J.R., Twigg, H.L. 3rd, and Martin, W.J. 2nd. (1995). Surfactant protein a promotes attachment of Mycobacterium tuberculosis to alveolar macrophages during infection with human immunodeficiency virus. Proc Natl Acad Sci U S A 92, 4848-4852.

Fairbanks, G., Steck, T.L., and Wallach, D.F. (1971). Electrophoretic analysis of the major polypeptides of the human erythrocyte membrane. Biochemistry 10, 2606-2617.

Feinberg, H., Mitchell, D.A., Drickamer, K., and Weis, W.I. (2001). Structural basis for selective recognition of oligosaccharides by DC-SIGN and DC-SIGNR. Science 294, 2163-2166.

Fenton, M.J., and Vermeulen, M.W. (1996). Immunopathology of tuberculosis: roles of macrophages and monocytes. Infect Immun 64, 683-690.

Friedland, J.S., Shattock, R., Remick, D.G., and Griffin, G.E. (1993). Mycobacterial $65-\mathrm{kD}$ heat shock protein induces release of proinflammatory cytokines from human monocytic cells. Clin Exp Immunol 91, 58-62.

Frisk, A., Ison, C.A., and Lagergård, T. (1998). GroEL heat shock protein of Haemophilus ducreyi: association with cell surface and capacity to bind to eukaryotic cells. Infect Immun 66, 1252-1257.

Gasteiger, E., Gattiker, A., Hoogland, C., Ivanyi, I., Appel, R.D., and Bairoch, A. (2003). ExPASy: The proteomics server for in-depth protein knowledge and analysis. Nucleic Acids Res 31, 3784-3788.

Gehring, A.J., Dobos, K.M., Belisle, J.T., Harding, C.V., and Boom, W. H. (2004). Mycobacterium tuberculosis LprG (Rv1411c): a novel TLR-2 ligand that inhibits human macrophage class II MHC antigen processing. J Immunol 173, 2660-2668.

Geijtenbeek, T.B., Torensma, R., van Vliet, S.J., van Duijnhoven, G. C., Adema, G.J., van Kooyk, Y., and Figdor, C.G. (2000a). Identification of DC-SIGN, a novel dendritic cell-specific ICAM-3 receptor that supports primary immune responses. Cell 100, 
575-585.

Geijtenbeek, T.B., Kwon, D.S., Torensma, R., van Vliet, S.J., van Duijnhoven, G.C., Middel, J., Cornelissen, I.L., Nottet, H.S., KewalRamani, V.N., Littman, D.R., et al. (2000b). DC-SIGN, a dendritic cell-specific HIV-1-binding protein that enhances transinfection of T cells. Cell 100, 587-597.

Geijtenbeek, T.B., Van Vliet, S.J., Koppel, E.A., Sanchez-Hernandez, M., Vandenbroucke-Grauls, C.M., Appelmelk, B., and Van Kooyk, Y. (2003). Mycobacteria target DC-SIGN to suppress dendritic cell function. J Exp Med 197, 7-17.

Gil-Navarro, I., Gil, M.L., Casanova, M., O'Connor, J.E., Martínez, J. P., and Gozalbo, D. (1997). The glycolytic enzyme glyceraldehyde3-phosphate dehydrogenase of Candida albicans is a surface antigen. J Bacteriol 179, 4992-4999.

Goudot-Crozel, V., Caillol, D., Djabali, M., and Dessein, A.J. (1989). The major parasite surface antigen associated with human resistance to schistosomiasis is a $37-k D$ glyceraldehyde-3Pdehydrogenase. J Exp Med 170, 2065-2080.

Gringhuis, S.I., den Dunnen, J., Litjens, M., van Het Hof, B., van Kooyk, Y., and Geijtenbeek, T.B. (2007). C-type lectin DC-SIGN modulates Toll-like receptor signaling via Raf-1 kinase-dependent acetylation of transcription factor NF-kappaB. Immunity 26, 605-616.

Gringhuis, S.I., den Dunnen, J., Litjens, M., van der Vlist, M., Geijtenbeek, T.B. (2009) Carbohydrate-specific signaling through the DC-SIGN signalosome tailors immunity to Mycobacterium tuberculosis, HIV-1 and Helicobacter pylori.

Guo, Y., Feinberg, H., Conroy, E., Mitchell, D.A., Alvarez, R., Blixt, O., Taylor, M.E., Weis, W.I., and Drickamer, K. (2004). Structural basis for distinct ligand-binding and targeting properties of the receptors DC-SIGN and DC-SIGNR. Nat Struct Mol Biol 11, 591-598.

Hanawa, T., Fukuda, M., Kawakami, H., Hirano, H., Kamiya, S., and Yamamoto, T. (1999). The Listeria monocytogenes DnaK chaperone is required for stress tolerance and efficient phagocytosis with macrophages. Cell Stress Chaperones 4, 118-128.

Henderson, R.A., Watkins, S.C., and Flynn, J.L. (1997). Activation of human dendritic cells following infection with Mycobacterium tuberculosis. J Immunol 159, 635-643.

Hennequin, C., Porcheray, F., Waligora-Dupriet, A., Collignon, A., Barc, M., Bourlioux, P., and Karjalainen, T. (2001). GroEL (Hsp60) of Clostridium difficile is involved in cell adherence. Microbiology 147, 87-96.

Herrmann, J.L., Delahay, R., Gallagher, A., Robertson, B., and Young, D. (2000). Analysis of post-translational modification of mycobacterial proteins using a cassette expression system. FEBS Lett 473, 358-362.

Hickey, T.B., Thorson, L.M., Speert, D.P., Daffé, M., and Stokes, R.W. (2009). Mycobacterium tuberculosis Cpn60.2 and DnaK are located on the bacterial surface, where Cpn60.2 facilitates efficient bacterial association with macrophages. Infect Immun 77, 3389-3401.

$\mathrm{Hu}$, Y., Henderson, B., Lund, P.A., Tormay, P., Ahmed, M.T., Gurcha, S.S., Besra, G.S., and Coates, A.R. (2008). A Mycobacterium tuberculosis mutant lacking the groEL homologue cpn60.1 is viable but fails to induce an inflammatory response in animal models of infection. Infect Immun 76, 1535-1546.

Jäkel, A., Clark, H., Reid, K.B.M., and Sim, R.B. (2010a). The human lung surfactant proteins $A(S P-A)$ and $D(S P-D)$ interact with apoptotic target cells by different binding mechanisms. Immunobiology 215, 551-558.

Jäkel, A., Reid, K.B.M., and Clark, H. (2010b). Surfactant protein A (SP-A) binds to phosphatidylserine and competes with annexin $\mathrm{V}$ binding on late apoptotic cells. Protein Cell 1, 188-197.

Jäkel, A., Clark, H., Reid, K.B.M., and Sim, R.B. (2010c). Surfacebound myeloperoxidase is a ligand for recognition of late apoptotic neutrophils by human lung surfactant proteins $A$ and $D$. Protein Cell 1, 563-572.

Jeffers, S.A., Tusell, S.M., Gillim-Ross, L., Hemmila, E.M., Achenbach, J.E., Babcock, G.J., Thomas, W.D. Jr, Thackray, L.B., Young, M.D., Mason, R.J., et al. (2004). CD209L (L-SIGN) is a receptor for severe acute respiratory syndrome coronavirus. Proc Natl Acad Sci U S A 101, 15748-15753.

Kenny, B., and Finlay, B.B. (1995). Protein secretion by enteropathogenic Escherichia coli is essential for transducing signals to epithelial cells. Proc Natl Acad Sci U S A 92, 7991-7995.

Kong, T.H., Coates, A.R., Butcher, P.D., Hickman, C.J., and Shinnick, T.M. (1993). Mycobacterium tuberculosis expresses two chaperonin-60 homologs. Proc Natl Acad Sci U S A 90, 2608-2612.

Krarup, A., Wallis, R., Presanis, J.S., Gál, P., Sim, R.B., and Sommer, P. (2007). Simultaneous activation of complement and coagulation by MBL-associated serine protease 2. PLoS ONE 2, e623.

Lee, B., Leslie, G., Soilleux, E., O’Doherty, U., Baik, S., Levroney, E., Flummerfelt, K., Swiggard, W., Coleman, N., Malim, M., et al. (2001). cis Expression of DC-SIGN allows for more efficient entry of human and simian immunodeficiency viruses via CD4 and a coreceptor. J Virol 75, 12028-12038.

Lewthwaite, J.C., Coates, A.R., Tormay, P., Singh, M., Mascagni, P., Poole, S., Roberts, M., Sharp, L., and Henderson, B. (2001). Mycobacterium tuberculosis chaperonin 60.1 is a more potent cytokine stimulator than chaperonin 60.2 (Hsp 65) and contains a CD14-binding domain. Infect Immun 69, 7349-7355.

Maeda, N., Nigou, J., Herrmann, J.L., Jackson, M., Amara, A., Lagrange, P.H., Puzo, G., Gicquel, B., and Neyrolles, O. (2003). The cell surface receptor DC-SIGN discriminates between Mycobacterium species through selective recognition of the mannose caps on lipoarabinomannan. J Biol Chem 278, 5513-5516.

Mitchell, D.A., Fadden, A.J., and Drickamer, K. (2001). A novel mechanism of carbohydrate recognition by the C-type lectins DCSIGN and DC-SIGNR. Subunit organization and binding to multivalent ligands. J Biol Chem 276, 28939-28945.

Pancholi, V., and Fischetti, V.A. (1992). A major surface protein on group A streptococci is a glyceraldehyde-3-phosphate-dehydrogenase with multiple binding activity. J Exp Med 176, 415-426.

Parker, A.E., and Bermudez, L.E. (2000). Sequence and characterization of the glyceraldehyde-3-phosphate dehydrogenase of Mycobacterium avium: correlation with an epidermal growth factor binding protein. Microb Pathog 28, 135-144.

Pasula, R., Downing, J.F., Wright, J.R., Kachel, D.L., Davis, T.E. Jr, and Martin, W.J. 2nd. (1997). Surfactant protein A (SP-A) mediates attachment of Mycobacterium tuberculosis to murine alveolar macrophages. Am J Respir Cell Mol Biol 17, 209-217.

Pitarque, S., Herrmann, J.L., Duteyrat, J.L., Jackson, M., Stewart, G. R., Lecointe, F., Payre, B., Schwartz, O., Young, D.B., Marchal, G., et al. (2005). Deciphering the molecular bases of Mycobacterium tuberculosis binding to the lectin DC-SIGN reveals an under- 
estimated complexity. Biochem J 392, 615-624.

Pöhlmann, S., Soilleux, E.J., Baribaud, F., Leslie, G.J., Morris, L.S., Trowsdale, J., Lee, B., Coleman, N., and Doms, R.W. (2001). DCSIGNR, a DC-SIGN homologue expressed in endothelial cells, binds to human and simian immunodeficiency viruses and activates infection in trans. Proc Natl Acad Sci U S A 98, 2670-2675.

Shevchenko, A., Tomas, H., Havlis, J., Olsen, J.V., and Mann, M. (2006). In-gel digestion for mass spectrometric characterization of proteins and proteomes. Nat Protoc 1, 2856-2860.

Soilleux, E.J., Barten, R., and Trowsdale, J. (2000). DC-SIGN; a related gene, DC-SIGNR; and CD23 form a cluster on 19p13. J Immunol 165, 2937-2942.

Sturgill-Koszycki, S., Schaible, U.E., and Russell, D.G. (1996). Mycobacterium-containing phagosomes are accessible to early endosomes and reflect a transitional state in normal phagosome biogenesis. EMBO J 15, 6960-6968.

Tailleux, L., Schwartz, O., Herrmann, J.L., Pivert, E., Jackson, M., Amara, A., Legres, L., Dreher, D., Nicod, L.P., Gluckman, J.C., et al. (2003). DC-SIGN is the major Mycobacterium tuberculosis receptor on human dendritic cells. J Exp Med 197, 121-127.

Takaya, A., Tomoyasu, T., Matsui, H., and Yamamoto, T. (2004). The DnaK/DnaJ chaperone machinery of Salmonella enterica serovar Typhimurium is essential for invasion of epithelial cells and survival within macrophages, leading to systemic infection. Infect Immun 72, 1364-1373.

van Kooyk, Y., and Geijtenbeek, T.B. (2003). DC-SIGN: escape mechanism for pathogens. Nat Rev Immunol 3, 697-709.

Vannberg, F.O., Chapman, S.J., Khor, C.C., Tosh, K., Floyd, S., Jackson-Sillah, D., Crampin, A., Sichali, L., Bah, B., Gustafson, P., et al. (2008). CD209 genetic polymorphism and tuberculosis disease. PLoS ONE 3, e1388.

Weikert, L.F., Edwards, K., Chroneos, Z.C., Hager, C., Hoffman, L., and Shepherd, V.L. (1997). SP-A enhances uptake of bacillus Calmette-Guérin by macrophages through a specific SP-A receptor. Am J Physiol 272, L989-L995.

Yamaguchi, H., Osaki, T., Taguchi, H., Hanawa, T., Yamamoto, T., and Kamiya, S. (1996). Flow cytometric analysis of the heat shock protein 60 expressed on the cell surface of Helicobacter pylori. J Med Microbiol 45, 270-277. 